\title{
Topical nonsteroidal anti-inflammatory drugs for management of osteoarthritis in long-term care patients
}

REVIEW

\author{
Charles E Argoff' \\ F Michael Gloth² \\ 'Albany Medical College and \\ Comprehensive Pain Center, \\ Albany Medical Center, Albany, NY, \\ USA; ${ }^{2}$ Johns Hopkins University \\ School of Medicine, Baltimore, \\ MD, USA
}

This article was published in the following Dove Press journal:

Therapeutics and Clinical Risk Management

19 September 2011

Number of times this article has been viewed

\begin{abstract}
Osteoarthritis is common in patients $\geq 65$ years of age. Although nonsteroidal anti-inflammatory drugs (NSAIDs) are often prescribed for osteoarthritis pain, they pose agerelated cardiovascular, renal, and gastrointestinal risks. Two topical NSAIDs, diclofenac sodium $1 \%$ gel (DSG) and diclofenac sodium 1.5\% in 45.5\% dimethylsulfoxide solution (D-DMSO), are approved in the US for the treatment of osteoarthritis pain. Topical NSAIDs have shown efficacy and safety in knee (DSG, D-DMSO) and hand (DSG) osteoarthritis. Analyses of data from randomized controlled trials of DSG in hand and knee osteoarthritis demonstrate significant improvement of pain and function in both younger patients $(<65$ years) and older patients ( $\geq 65$ years) and suggest good safety and tolerability. However, long-term safety data in older patients are limited. Topical NSAIDs can ease medication administration and help address barriers to pain management in older patients, such as taking multiple medications and inability to swallow, and are a valuable option for long-term care providers.
\end{abstract}

Keywords: nonsteroidal anti-inflammatory drugs, long-term care, nursing homes, chronic pain, topical analgesics

\section{Introduction}

Osteoarthritis affects many older persons aged $\geq 65$ years. Knee osteoarthritis occurs in more than $32 \%$ of these individuals, ${ }^{1}$ and hand osteoarthritis occurs in more than $50 \%$ of older patients. ${ }^{2}$ A multitude of treatment modalities are available for patients with osteoarthritis, among which a balance between efficacy, safety, and convenience must be found to achieve successful long-term management of symptoms. An algorithm has been proposed as an aid to navigating the clinical options (see Figure 1). ${ }^{3}$

Treatment of osteoarthritis begins with education of patients about the disease and nonpharmacological interventions to minimize pain and improve function. These include measures such as exercise to improve strength and range of motion, pacing of activities, weight reduction, use of braces or splints, application of heat, and acupuncture. ${ }^{4,5}$ However, the treatment of osteoarthritis typically requires a combination of nonpharmacologic and pharmacologic interventions.

For patients in need of pharmacotherapy, acetaminophen (paracetamol) is among the mainstays of pharmacologic agents that rapidly relieve symptoms and is recommended as first-line therapy by most osteoarthritis treatment guidelines. ${ }^{4,5}$ Other orally administered drugs, such as tramadol, opioids, selective serotonin reuptake inhibitors, and serotonin-norepinephrine reuptake inhibitors are used as second-line treatment or adjunctively. Topically applied products are usually also indicated as second-line agents, some of which (eg, salicylates and the lidocaine $5 \%$ patch) are available only
Correspondence: Charles E Argoff Albany Medical College, $47 \mathrm{New}$ Scotland Ave, MC70, Physician's Pavilion,

Ist Floor, Albany, NY 12208, USA

$\mathrm{Tel}+\mathrm{I} 5182625226$

Fax + I $518262504 \mid$

Email cargoff@nycap.rr.com 


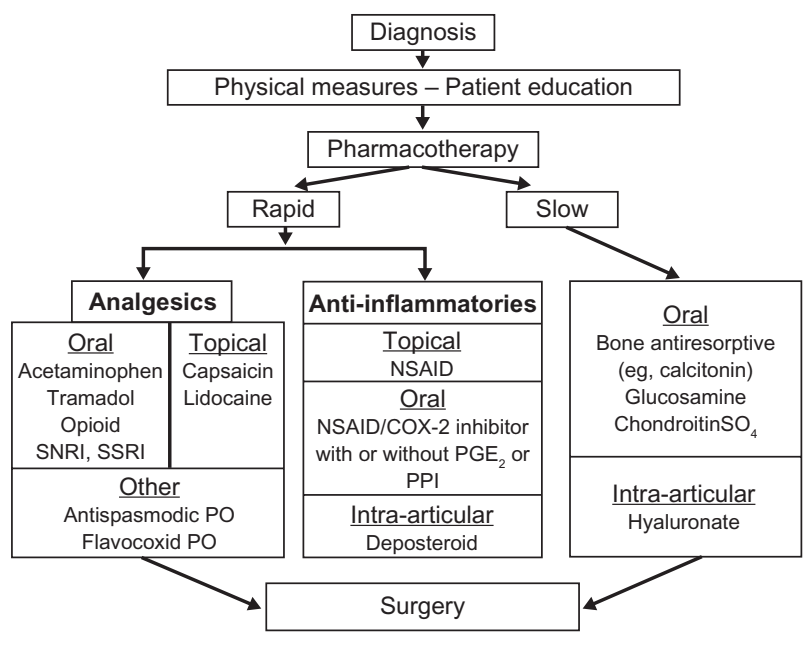

Figure I Treatment algorithm for symptomatic osteoarthritis.

Abbreviations: COX-2, cyclo-oxygenase-2; IV, intravenous; NSAID, nonsteroidal anti-inflammatory drug; $\mathrm{PGE}_{2}$, prostaglandin $\mathrm{E}_{2}$; $\mathrm{PPI}$, proton pump inhibitor; $\mathrm{PO}$, oral; SNRI, selective norepinephrine reuptake inhibitor; SSRI, selective serotonin reuptake inhibitor.

in a topical form. Although frequently prescribed for osteoarthritis pain, it should be noted that the lidocaine $5 \%$ patch is approved in the US only for postherpetic neuralgia. ${ }^{6}$ Some guidelines give topical treatments precedence over systemic treatments for patients with osteoarthritis of the hand. ${ }^{4}$

Nonsteroidal anti-inflammatory drugs (NSAIDs) are also frequently prescribed for osteoarthritis pain, but have agerelated risks of cardiovascular, ${ }^{7}$ renal, ${ }^{8}$ and gastrointestinal adverse events. ${ }^{9}$ To minimize risks, treatment guidelines for chronic pain ${ }^{4,5,10-12}$ recommend rare and cautious use of oral NSAIDs in the elderly. Guidelines ${ }^{4,5,13}$ also suggest limiting NSAID exposure by prescribing the lowest effective dose for the shortest possible duration, typically with a gastroprotective agent, such as a proton pump inhibitor, or misoprostol, prostaglandin $\mathrm{E}_{1}$ analog. A recent review concluded that NSAIDs are appropriate for use in older patients, as long as medical history, comorbid conditions, and concomitant medications are taken into consideration.

Topical NSAIDs may limit NSAID exposure by acting locally with less systemic distribution. Two topical NSAIDs are approved in the US for treating osteoarthritis pain, ie, diclofenac sodium $1 \%$ gel (DSG, Voltaren ${ }^{\circledR}$ Gel, Endo Pharmaceuticals Inc, Chadds Ford, PA) and diclofenac sodium $1.5 \%$ in $45.5 \%$ dimethylsulfoxide solution (D-DMSO, Pennsaid $^{\circledR}$, Mallinckrodt Pharmaceuticals Inc, Hazelwood, MO). Topical diclofenac is effectively absorbed in the knee ${ }^{14}$ and hand; ${ }^{15}$ however, plasma concentrations remain very low. Clinical trial data support the efficacy and safety of $\mathrm{DSG}^{16,17}$ and D-DMSO ${ }^{18,19}$ in patients with knee osteoarthritis and DSG in hand osteoarthritis. ${ }^{20}$ Effect sizes calculated for DSG and D-DMSO indicate that the two topical diclofenac formulations show efficacy similar to that of oral NSAIDs. ${ }^{21}$ A recent review has summarized and compared clinical study data on the various available topical NSAID products as tested in general populations of patients with knee or hand osteoarthritis. $^{22}$

It is the purpose of this article to briefly review clinical data on topical NSAIDs for osteoarthritis pain in older and younger patients. Safety and efficacy results, irrespective of age, and the role of topical NSAIDs in long-term care will be discussed.

\section{Age-related NSAID risks}

NSAIDS, particularly cyclo-oxygenase-2 inhibitors, are associated with an increased risk of cardiovascular adverse events ${ }^{7}$ and clinically meaningful increases in blood pressure. ${ }^{23}$ Because cardiovascular disease increases with age,${ }^{24}$ older patients are particularly susceptible to these events. ${ }^{7}$ Similarly, NSAIDs are more likely to cause renal adverse events in older patients. ${ }^{8}$ Moreover, acid-related disorders (ie, ulcers) increase with age, ${ }^{25}$ and epidemiologic studies suggest that approximately $90 \%$ of patients with osteoarthritis have an increased risk of gastrointestinal bleeding. ${ }^{26}$ Although cyclo-oxygenase- 2 inhibitors were developed to minimize gastrointestinal risk, population-based studies provide limited support for improved tolerability. ${ }^{9}$ For topical NSAID formulations with DMSO, which is both a solvent and an enhancer of dermal penetration, ${ }^{27}$ age-related skin changes could in theory increase NSAID absorption, although no data are available to confirm or refute this hypothesis. However, the penetration-enhancing effects of DMSO are maximized only at concentrations $>60 \%,{ }^{27}$ which is greater than the $45.5 \%$ concentration in D-DMSO.

Older patients with osteoarthritis are likely to have comorbidities requiring medications that may adversely interact with some osteoarthritis pharmacotherapies. ${ }^{28}$ Warfarin treatment in patients taking NSAIDs increases bleeding risk. ${ }^{29}$ Selective serotonin reuptake inhibitors, serotonin-norepinephrine reuptake inhibitors, and corticosteroids can also increase bleeding risk. ${ }^{11}$ Antihypertensives lose effectiveness when administered with certain NSAIDs, ${ }^{30}$ and ibuprofen may neutralize the cardioprotective effects of low-dose aspirin. ${ }^{31}$ Proton pump inhibitors (administered for gastroprotection during NSAID therapy) can neutralize the therapeutic effects of clopidogrel, increasing the risk of myocardial infarction. ${ }^{32}$ 


\section{Efficacy of topical NSAIDs in elderly patients}

The efficacy of DSG and vehicle gel for the treatment of knee osteoarthritis was compared in older patients (aged $\geq 65$ years; DSG, $\mathrm{n}=189$; vehicle, $\mathrm{n}=185$ ) vs younger patients (aged $<65$ years; DSG, $\mathrm{n}=301$; vehicle, $\mathrm{n}=301$ ) in a pooled analysis of three 12-week, randomized, doubleblind trials. Efficacy measures included the Western Ontario and McMaster Universities Osteoarthritis Index pain and physical function subscales, a global rating of disease, and pain on movement.

In older patients, improvements from baseline in all outcome measures ranged from $39 \%$ to $46 \%$ with DSG and from $28 \%$ to $35 \%$ with vehicle; in younger patients, improvements ranged from $45 \%$ to $50 \%$ with DSG and $35 \%$ to $39 \%$ with vehicle (Table 1). Improvements with DSG were significant for pain, function, and pain on movement in older patients and for all outcome measures in younger patients.

Notably, topical diclofenac is indicated as monotherapy for patients with osteoarthritis limited to a few superficial joints. However, some guidelines recommend using topical NSAIDs as an adjunctive therapy for osteoarthritis pain., ${ }^{5,12}$ A recent study of D-DMSO included a treatment arm that modeled adjunctive use of topical NSAIDs for knee osteoarthritis pain. ${ }^{19}$ In this 12 -week, five-arm, 775-patient trial, an oral diclofenac/topical D-DMSO combination was not more effective than oral diclofenac alone, suggesting that topical
NSAIDs cannot effectively augment the analgesia provided by oral NSAIDs. However, no significant differences between D-DMSO alone and oral diclofenac alone occurred for any efficacy outcome, indicating that oral diclofenac offered no advantage over topical diclofenac for knee osteoarthritis. Therefore, the decision to use a topical vs an oral NSAID should be based on the location and extent of the osteoarthritis, not the severity of the pain. For osteoarthritis pain localized to a few superficial joints, oral NSAIDs offer no advantage over topical NSAIDs.

\section{Tolerability of topical NSAIDs in elderly patients}

Pooled data from five randomized controlled trials assessed DSG safety in older ( $\geq 65$ years) and younger ( $<65$ years) patients, ie, three trials in patients with knee osteoarthritis $(\mathrm{n}=1426)$ and two trials in patients with hand osteoarthritis $(n=783) .{ }^{33}$ Irrespective of osteoarthritis type or age, adverse events were more frequent on DSG than on vehicle (Table 2), mostly owing to a higher rate of application site adverse events with DSG. Gastrointestinal and other systemic adverse events occurred with similar frequency in the two treatment groups. In knee osteoarthritis trials, three patients applying DSG ( $\geq 65$ years, $n=1 ;<65$ years, $n=2$ ) and two applying vehicle (one patient per age group) experienced treatment-related gastrointestinal adverse events. In the hand osteoarthritis trials, two DSG-treated patients (one per age

Table I Key outcome measures in patients with knee osteoarthritis

\begin{tabular}{|c|c|c|c|c|}
\hline \multirow[t]{2}{*}{ Outcome measure } & \multicolumn{2}{|c|}{ Patients aged $<65$ years } & \multicolumn{2}{|c|}{ Patients aged $\geq 65$ years } \\
\hline & DSG $(n=301)$ & Vehicle $(n=301)$ & DSG $(n=189)$ & Vehicle $(n=185)$ \\
\hline Mean (SD) baseline WOMAC pain & $12.3(2.7)$ & $12.3(2.7)$ & I2.I (2.6) & II.8 (2.5) \\
\hline LS mean change from baseline & $-5.8^{\mathrm{a}}$ & -4.7 & $-5.3^{\mathrm{b}}$ & $-4.1^{b}$ \\
\hline SE & 0.28 & 0.28 & 0.34 & 0.35 \\
\hline Percentage change from baseline & 47.2 & 38.2 & 43.8 & 34.7 \\
\hline Mean (SD) baseline WOMAC function & $40.2(10.8)$ & $40.5(11.1)$ & $40.3(11.0)$ & $38.8(10.9)$ \\
\hline LS mean change from baseline & $-17.9^{a}$ & -14.2 & $-15.5^{\mathrm{a}}$ & -11.0 \\
\hline SE & 0.9 & 0.9 & I.I & I.I \\
\hline Percentage change from baseline & 44.5 & 35.1 & 38.5 & 28.4 \\
\hline Mean (SD) baseline GRD & $63.0(19.5)$ & $63.3(18.8)$ & $61.8(18.9)$ & $61.4(21.9)$ \\
\hline LS mean change from baseline & $-29.5^{c}$ & -23.8 & -23.8 & -18.7 \\
\hline SE & 1.6 & 1.7 & 2.0 & 2.1 \\
\hline Percentage change from baseline & 46.8 & 37.6 & 38.5 & 30.4 \\
\hline Mean (SD) baseline POM & $75.3(11.7)$ & $74.7(12.2)$ & $74.1(11.8)$ & $74.7(12.0)$ \\
\hline LS mean POM & $-37.3^{d}$ & -29.0 & $-33.7^{\mathrm{b}}$ & -26.4 \\
\hline SE & 1.8 & 1.8 & 2.2 & 2.2 \\
\hline Percentage change from baseline & 49.5 & 38.8 & 45.5 & 35.3 \\
\hline
\end{tabular}

Notes: ${ }^{\mathrm{P} P}<0.01$ for diclofenac sodium $1 \%$ gel vs vehicle; ${ }^{\mathrm{b}} P=0.02$ for diclofenac sodium $1 \%$ gel vs vehicle; ${ }^{\mathrm{c}} P=0.0 \mathrm{I}$ for diclofenac sodium $1 \%$ gel vs vehicle; ${ }^{\mathrm{d} P}<0.00 \mathrm{I}$ for diclofenac sodium $1 \%$ gel vs vehicle.

Abbreviations: DSG, diclofenac sodium I\% gel; GRD, global rating of disease; LS, least squares; POM, pain on movement; SD, standard deviation; SE, standard error of the mean; WOMAC, Western Ontario and McMaster Universities Osteoarthritis Index. 
group) and one vehicle-treated patient ( $<65$ years) experienced treatment-related gastrointestinal adverse events. Cardiovascular, renal, and hepatic adverse events occurred with similar frequency on DSG and vehicle in older and younger patients. Only one serious adverse event, ie, deep vein thrombosis with pulmonary embolism in an 80-year-old woman with hypertension and type 2 diabetes, was deemed potentially related to treatment. The adverse event was considered mild in severity and was managed successfully with warfarin and heparin.

In the 12-week, five-arm, 775-patient trial of D-DMSO, ${ }^{19}$ the combination of oral diclofenac with D-DMSO was not associated with an increased incidence of systemic adverse events compared with oral diclofenac alone. In particular, gastrointestinal adverse events were reported in $23.8 \%$ of patients treated with oral diclofenac alone and $25.7 \%$ of those receiving oral and topical diclofenac concurrently. Patients treated with D-DMSO alone had a lower incidence of gastrointestinal adverse events than did those assigned to placebo (6.5\% vs 9.6\%). These results suggest that D-DMSO acted locally, producing systemic cyclo-oxygenase inhibition insufficient for a clinically meaningful increase in the cyclo-oxygenase inhibition achieved with the oral NSAID alone. Although the results of this trial were not stratified by age, the mean \pm standard deviation ages by treatment group were $61.7 \pm 9.8$ years in the D-DMSO group, $62 \pm 10.5$ years in the oral diclofenac group, and $60.6 \pm 10.0$ years in the group taking oral and topical diclofenac concurrently. This indicates that the study population included numerous seniors. No serious adverse event was reported in any patient treated with D-DMSO, regardless of age.

Table 2 Total and most frequent adverse events ( $\geq 3 \%$ of randomized patients in any group) in patients with knee or hand osteoarthritis

\begin{tabular}{|c|c|c|c|c|c|c|c|c|}
\hline \multirow[t]{3}{*}{ Adverse event, $n$ (\%) } & \multicolumn{4}{|c|}{ Patients with knee osteoarthritis } & \multicolumn{4}{|c|}{ Patients with hand osteoarthritis } \\
\hline & \multicolumn{2}{|c|}{ Aged $<65$ years } & \multicolumn{2}{|c|}{ Aged $\geq 65$ years } & \multicolumn{2}{|c|}{ Aged $<65$ years } & \multicolumn{2}{|c|}{ Aged $\geq 65$ years } \\
\hline & $\begin{array}{l}\text { DSG } \\
(n=447)\end{array}$ & $\begin{array}{l}\text { Vehicle } \\
(n=44 I)\end{array}$ & $\begin{array}{l}\text { DSG } \\
(n=274)\end{array}$ & $\begin{array}{l}\text { Vehicle } \\
(n=264)\end{array}$ & $\begin{array}{l}\text { DSG } \\
(n=2 \mid 5)\end{array}$ & $\begin{array}{l}\text { Vehicle } \\
(n=2 \mid 5)\end{array}$ & $\begin{array}{l}\text { DSG } \\
(n=185)\end{array}$ & $\begin{array}{l}\text { Vehicle } \\
(n=168)\end{array}$ \\
\hline Any AE & $253(56.6)$ & $224(50.8)$ & $153(55.8)$ & $116(43.9)$ & $84(39.1)$ & $81(37.7)$ & $79(42.7)$ & $58(34.5)$ \\
\hline Serious $A E s^{a}$ & $5(I . I)$ & $2(0.5)$ & $7(2.6)$ & $3(1.1)$ & $2(0.9)$ & $2(0.9)$ & $2(1.1)$ & $2(1.2)$ \\
\hline Deaths $^{\mathrm{b}}$ & 0 & 0 & $\mathrm{I}(0.4)$ & 0 & 0 & 0 & 0 & 0 \\
\hline Gastrointestinal AEs & $23(5.1)$ & $20(4.5)$ & II (4.0) & II (4.2) & $10(4.7)$ & $10(4.7)$ & $13(7.0)$ & $7(4.2)$ \\
\hline Application site AEs & $25(5.6)$ & $8(1.8)$ & $24(8.8)$ & $3(1.1)$ & $7(3.3)$ & $4(1.9)$ & II (5.9) & $4(2.4)$ \\
\hline CV AEs & $9(2.0)$ & $5(1.1)$ & $5(1.8)$ & $3(1.1)$ & $\mathrm{I}(0.5)$ & $2(0.9)$ & $\mathrm{I}(0.5)$ & $\mathrm{I}(0.6)$ \\
\hline Angina pectoris & $\mathrm{I}(0.2)$ & $\mathrm{I}(0.2)$ & 0 & 0 & 0 & 0 & 0 & 0 \\
\hline Atrial fibrillation & $\mathrm{I}(0.2)$ & 0 & 0 & 0 & 0 & 0 & 0 & 0 \\
\hline Coronary stent surgery & 0 & 0 & 0 & 0 & 0 & 0 & 0 & I (0.6) \\
\hline Deep vein thrombosis ${ }^{\mathrm{a}}$ & 0 & 0 & $\mathrm{I}(0.4)$ & 0 & 0 & 0 & 0 & 0 \\
\hline Orthostatic hypotension & 0 & 0 & $\mathrm{I}(0.4)$ & 0 & 0 & 0 & 0 & 0 \\
\hline Palpitations & $\mathrm{I}(0.2)$ & 0 & 0 & $\mathrm{I}(0.4)$ & 0 & 0 & 0 & 0 \\
\hline Sinus arrhythmia & $\mathrm{I}(0.2)$ & 0 & 0 & 0 & 0 & 0 & 0 & 0 \\
\hline Supraventricular extrasystoles & 0 & $\mathrm{I}(0.2)$ & 0 & 0 & 0 & 0 & 0 & 0 \\
\hline Tachycardia & $\mathrm{I}(0.2)$ & 0 & 0 & 0 & 0 & 0 & 0 & 0 \\
\hline Ventricular fibrillation ${ }^{\mathrm{b}}$ & 0 & 0 & $\mathrm{I}(0.4)$ & 0 & 0 & 0 & 0 & 0 \\
\hline Worsening hypertension & $6(1.3)$ & $3(0.7)$ & $2(0.7)$ & $2(0.8)$ & $\mathrm{I}(0.5)$ & $2(0.9)$ & $\mathrm{I}(0.5)$ & 0 \\
\hline Renal $A E s^{c}$ & $2(0.4)$ & $\mathrm{I}(0.2)$ & $3(1.1)$ & $\mathrm{I}(0.4)$ & 0 & I $(0.5)$ & 0 & 0 \\
\hline Blood creatinine increased & 0 & $\mathrm{I}(0.2)$ & $2(0.7)$ & $\mathrm{I}(0.4)$ & 0 & 0 & 0 & 0 \\
\hline Diabetic nephropathy & 0 & 0 & 0 & 0 & 0 & $\mathrm{I}(0.5)$ & 0 & 0 \\
\hline Hematuria & $\mathrm{I}(0.2)$ & 0 & 0 & 0 & 0 & 0 & 0 & 0 \\
\hline Nephrolithiasis & $\mathrm{I}(0.2)$ & 0 & 0 & 0 & 0 & 0 & 0 & 0 \\
\hline Pollakiuria & 0 & 0 & $\mathrm{I}(0.4)$ & 0 & 0 & 0 & 0 & 0 \\
\hline Hepatic AEs & $\mathrm{I}(0.2)$ & $3(0.7)$ & $\mathrm{I}(0.4)$ & $3(1.2)$ & $\mathrm{I}(0.5)$ & 0 & 0 & $2(1.2)$ \\
\hline Elevated alanine aminotransferase & $\mathrm{I}(0.2)$ & $3(0.7)$ & 0 & $\mathrm{I}(0.4)$ & $\mathrm{I}(0.5)$ & 0 & 0 & $\mathrm{I}(0.6)$ \\
\hline Elevated aspartate aminotransferase & $\mathrm{I}(0.2)$ & $3(0.7)$ & 0 & 0 & 0 & 0 & 0 & I (0.6) \\
\hline Elevated gamma-glutamyltransferase & $\mathrm{I}(0.2)$ & 0 & $\mathrm{I}(0.4)$ & $2(0.8)$ & 0 & 0 & 0 & I (0.6) \\
\hline
\end{tabular}

Notes: ane serious, possibly treatment-related CV AE (deep vein thrombosis and pulmonary embolism) occurred in an 80-year-old woman with hypertension and T2DM. No other serious AE or CV AE was considered treatment-related; bone fatal, nontreatment-related CV AE (ventricular fibrillation) occurred in a 76-year-old man without T2DM, hypertension, or CV disease; 'Treatment-related blood creatinine increases occurred in one patient who received DSG and two who received vehicle. No other renal $A E$ was treatment-related.

Abbreviations: AE, adverse event; CV, cardiovascular; DSG, diclofenac sodium I\% gel; T2DM, type 2 diabetes mellitus. 
A 1-year, open-label trial assessed the long-term safety of DSG in 578 patients with knee osteoarthritis; ${ }^{34} 291$ patients completed one of the 12-week trials described earlier, and 292 were naive to topical NSAID therapy. The study included $208(36.0 \%)$ patients aged 60-70 years, $113(19.6 \%)$ patients aged $70-80$ years, and $13(2.2 \%)$ patients aged $>80$ years. Twenty-nine patients experienced a total of 36 serious adverse events. One serious adverse event was considered potentially treatment-related, ie, deep vein thrombosis with pulmonary embolism (described above), which occurred in one patient during the randomized controlled trial preceding this open-label study. Similarly, a 1-year, open-label study of D-DMSO assessed its long-term safety in patients who completed the five-arm trial described earlier $(n=221)$ as well as newly enrolled patients $(\mathrm{n}=572) .{ }^{35}$ The mean age was $62.5 \pm 10.1$ years, indicating that the population included numerous seniors. The tolerability of D-DMSO during long-term therapy was similar to that seen in the short-term studies, with application site reactions constituting the most common adverse events and systemic adverse events occurring infrequently.

Thus, short-term (12-week) data on DSG and D-DMSO show good safety and tolerability in older patients, and open-label study data provide preliminary evidence of long-term safety. Nonetheless, few long-term safety data in older patients exist, particularly for patients aged $>80$ years. Until such data are available, topical NSAIDs should be avoided in patients with absolute contraindications to oral NSAIDs and used with caution in patients with relative contraindications.

\section{Unique needs of long-term care patients}

A correlation exists between inadequately controlled pain and impairment of activities of daily living and need for extensive supervision. ${ }^{36}$ For patients with osteoarthritis residing in long-term care facilities, symptomatic osteoarthritis of the hand and knee complicate care. Hand osteoarthritis is associated with feelings of dependence and embarrassment and the inability to carry out normal tasks. ${ }^{37}$ Knee osteoarthritis is associated with impaired mobility and increased risk of falls resulting in fractures. ${ }^{38}$ Unfortunately, the structural changes that impair function in osteoarthritis are not reversed or modified by current pharmacologic therapies, and many long-term care patients are medically unfit for orthopedic surgical interventions.

Despite having no disease-modifying mechanism of action, topical NSAIDs improve physical function and reduce joint stiffness in knee ${ }^{16,18,39}$ and hand ${ }^{20}$ osteoarthritis. Post hoc analyses of randomized controlled trials of topical NSAIDs in knee $^{40}$ and hand ${ }^{41}$ osteoarthritis show a correlation between pain relief and improvements in physical function, regardless of active vs placebo treatment. Evidently, some loss of function in hand and knee osteoarthritis results from voluntary or involuntary restriction of movement in response to pain, not structural limitations. Thus, any pain reduction may improve function.

Assessing and effectively treating pain in long-term care patients is challenging. Elderly patients may be reluctant to report pain, believing that recognition of pain is a sign of weakness, progression of illness, or impending death. ${ }^{42}$ Patients with (vs without) cognitive impairment are much less likely to report chronic pain, even if pain is expected, and are less likely to receive analgesics. ${ }^{43}$ Approximately half of nursing home patients receive analgesics as needed rather than regularly, ${ }^{43}$ increasing the likelihood of undertreatment in patients unable to report pain. However, even patients who report pain may be unable to comply with prescribed treatment regimens. Up to $50 \%$ of nursing home patients experience dysphagia, complicating treatment with oral medications. ${ }^{44}$ Taking of multiple medications, which is common in older patients, is associated with poor adherence ${ }^{45}$ and drug interactions. ${ }^{28}$ Using topical NSAIDs allows for regular, scheduled administration of effective analgesia without increasing pill counts and despite swallowing ability. In clinical trials of topical NSAID therapy, patient adherence to treatment ranged from $>75 \%$ to $94 \% .{ }^{16-20}$

Easy administration of a topical formulation is beneficial in the long-term care setting. Application of a gel or solution by the caregiver is less disruptive than giving a pill and does not require observation or assurance of ingestion. Further, although not widely studied, treatment incorporating physical contact provides comfort, reduces anxiety, and promotes a sense of well-being in nursing home residents. ${ }^{46}$ However, the value of topical administration toward adherence and psychologic benefit may be somewhat offset by the time that nursing home staff must spend applying topical products.

\section{Conclusion}

Given concerns about the safety of NSAIDs, particularly in older patients, the availability of topical diclofenac formulations in the US offers long-term care providers a valuable means of limiting NSAID exposure in patients with osteoarthritis in a few superficial joints. The topical formulation may also facilitate administration of medication in a long-term care population. 


\section{Disclosure}

This research was funded by Endo Pharmaceuticals Inc.

\section{References}

1. Dawson J, Linsell L, Zondervan K, et al. Epidemiology of hip and knee pain and its impact on overall health status in older adults. Rheumatology (Oxford). 2004;43(4):497-504.

2. Wilder FV, Barrett JP, Farina EJ. Joint-specific prevalence of osteoarthritis of the hand. Osteoarthritis Cartilage. 2006;14(9):953-957.

3. Altman RD. New guidelines for topical NSAIDs in the osteoarthritis treatment paradigm. Curr Med Res Opin. 2010;26(12): 2871-2876.

4. Zhang W, Doherty M, Leeb BF, et al. EULAR evidence based recommendations for the management of hand osteoarthritis: Report of a Task Force of the EULAR Standing Committee for International Clinical Studies Including Therapeutics (ESCISIT). Ann Rheum Dis. 2007;66(3):377-388.

5. Zhang W, Moskowitz RW, Nuki G, et al. OARSI recommendations for the management of hip and knee osteoarthritis, part II: OARSI evidence-based, expert consensus guidelines. Osteoarthritis Cartilage. 2008;16(2):137-162.

6. Yoo JH, Lim BO, Ha M, et al. A meta-analysis of the effect of neuromuscular training on the prevention of the anterior cruciate ligament injury in female athletes. Knee Surg Sports Traumatol Arthrosc. 2010;18(6):824-830.

7. Motsko SP, Rascati KL, Busti AJ, et al. Temporal relationship between use of NSAIDs, including selective COX-2 inhibitors, and cardiovascular risk. Drug Saf. 2006;29(7):621-632.

8. Barkin RL, Buvanendran A. Focus on the COX-1 and COX-2 agents: Renal events of nonsteroidal and anti-inflammatory drugs-NSAIDs. Am J Ther. 2004;11(2):124-129.

9. Hippisley-Cox J, Coupland C, Logan R. Risk of adverse gastrointestinal outcomes in patients taking cyclo-oxygenase- 2 inhibitors or conventional non-steroidal anti-inflammatory drugs: Population based nested case-control analysis. BMJ. 2005;331(7528):1310-1316.

10. American Academy of Orthopaedic Surgeons. Treatment of Osteoarthritis of the Knee (Non-arthroplasty). Rosemont, IL: American Academy of Orthopaedic Surgeons; 2008.

11. American Geriatrics Society. Pharmacological management of persistent pain in older persons. $J$ Am Geriatr Soc. 2009;57(8):1331-1346.

12. National Collaborating Centre for Chronic Conditions. Osteoarthritis: The Care and Management of Osteoarthritis in Adults. London, UK: Royal College of Physicians; 2008.

13. Rostom A, Moayyedi P, Hunt R; Canadian Association of Gastroenterology Consensus Group. Canadian consensus guidelines on long-term nonsteroidal anti-inflammatory drug therapy and the need for gastroprotection: Benefits versus risks. Aliment Pharmacol Ther. 2009;29(5):481-496.

14. Gondalf-Zink B, Gronwald U. [Active substance concentration in articular and periarticular tissues of the knee joint after cutaneous application of diclofenac-diethylammonium Emulgel]. Aktuelle Rheumatologie. 1996;21:298-304. French.

15. Riess W, Schmid K, Botta L, et al. The percutaneous absorption of diclofenac. Arzneimittelforschung. 1986;36(7):1092-1096.

16. Baraf HS, Gold MS, Clark MB, Altman RD. Safety and efficacy of topical diclofenac sodium $1 \%$ gel in knee osteoarthritis: A randomized controlled trial. Phys Sportsmed. 2010;38(2):19-28.

17. Barthel HR, Haselwood D, Longley S, 3rd, Gold MS, Altman RD. Randomized controlled trial of diclofenac sodium gel in knee osteoarthritis. Semin Arthritis Rheum. 2009;39(3):203-212.

18. Roth SH, Shainhouse JZ. Efficacy and safety of a topical diclofenac solution (Pennsaid) in the treatment of primary osteoarthritis of the knee: A randomized, double-blind, vehicle-controlled clinical trial. Arch Intern Med. 2004;164(18):2017-2023.
19. Simon LS, Grierson LM, Naseer Z, Bookman AA, Zev Shainhouse J. Efficacy and safety of topical diclofenac containing dimethyl sulfoxide (DMSO) compared with those of topical placebo, DMSO vehicle and oral diclofenac for knee osteoarthritis. Pain. 2009;143(3): 238-245.

20. Altman RD, Dreiser RL, Fisher CL, Chase WF, Dreher DS, Zacher J. Diclofenac sodium gel in patients with primary hand osteoarthritis: A randomized, double-blind, placebo-controlled trial. $J$ Rheumatol. 2009;36(9):1991-1999.

21. Barthel HR, Axford-Gatley RA. The importance of differentiating between topical NSAIDs (author reply). Postgrad Med. 2011. In press.

22. Barthel HR, Axford-Gatley RA. Topical nonsteroidal anti-inflammatory drugs for osteoarthritis. Postgrad Med. 2010;122(6):98-106.

23. Johnson AG, Nguyen TV, Day RO. Do nonsteroidal anti-inflammatory drugs affect blood pressure? A meta-analysis. Ann Intern Med. 1994;121(4):289-300.

24. Rosamond W, Flegal K, Friday G, et al. Heart disease and stroke statistics - 2007 update: A report from the American Heart Association Statistics Committee and Stroke Statistics Subcommittee. Circulation. 2007;115(5):e69-171

25. Higham J, Kang JY, Majeed A. Recent trends in admissions and mortality due to peptic ulcer in England: Increasing frequency of haemorrhage among older subjects. Gut. 2002;50(4):460-464.

26. Lanas A, Tornero J, Zamorano JL. Assessment of gastrointestinal and cardiovascular risk in patients with osteoarthritis who require NSAIDs: The LOGICA study. Ann Rheum Dis. 2010;69(8):1453-1458.

27. Williams AC, Barry BW. Penetration enhancers. Adv Drug Deliv Rev. 2004;56(5):603-618.

28. Tulner LR, Frankfort SV, Gijsen GJ, van Campen JP, Koks CH, Beijnen $\mathrm{JH}$. Drug-drug interactions in a geriatric outpatient cohort: Prevalence and relevance. Drugs Aging. 2008;25(4):343-355.

29. Cheetham TC, Levy G, Niu F, Bixler F. Gastrointestinal safety of nonsteroidal antiinflammatory drugs and selective cyclooxygenase-2 inhibitors in patients on warfarin. Ann Pharmacother. 2009;43(11):1765-1773.

30. Pavlicevic I, Kuzmanic M, Rumboldt M, Rumboldt Z. Interaction between antihypertensives and NSAIDs in primary care: A controlled trial. Can J Clin Pharmacol. 2008;15(3):e372-e382.

31. Farkouh ME, Greenberg JD, Jeger RV, et al. Cardiovascular outcomes in high risk patients with osteoarthritis treated with ibuprofen, naproxen or lumiracoxib. Ann Rheum Dis. 2007;66(6):764-770.

32. Ho PM, Maddox TM, Wang L, et al. Risk of adverse outcomes associated with concomitant use of clopidogrel and proton pump inhibitors following acute coronary syndrome. JAMA. 2009;301(9):937-944.

33. Baraf HS, Gold MS, Petruschke RA, Wieman MS. The tolerability of topical diclofenac sodium $1 \%$ gel for osteoarthritis in seniors and patients with comorbidities. Am J Geriatr Pharmacol. 2011. In press.

34. Peniston JH, Gold MS, Clark MB, Alwine LK. An open-label long-term safety trial of diclofenac sodium $1 \%$ gel in patients with osteoarthritis of the knee. Presented at the American Osteopathic Association 2009 Osteopathic Medical Conference and Exposition, November 1-5, 2009, New Orleans, LA.

35. Shainhouse JZ, Grierson LM, Naseer Z. A long-term, open-label study to confirm the safety of topical diclofenac solution containing dimethyl sulfoxide in the treatment of the osteoarthritic knee. Am J Ther. 2010;17(6):566-576.

36. Won A, Lapane K, Gambassi G, Bernabei R, Mor V, Lipsitz LA. Correlates and management of nonmalignant pain in the nursing home. SAGE Study Group. Systematic assessment of geriatric drug use via epidemiology. J Am Geriatr Soc. 1999;47(8):936-942.

37. Hill S, Dziedzic KS, Ong BN. The functional and psychological impact of hand osteoarthritis. Chronic Illn. 2010;6(2):101-110.

38. Arden NK, Crozier S, Smith H, et al. Knee pain, knee osteoarthritis, and the risk of fracture. Arthritis Rheum. 2006;55(4):610-615. 
39. Barthel HR, Haselwood D, Longley S, Gold MS, Altman RD. Diclofenac sodium topical gel $1 \%$ in patients with primary knee osteoarthritis: A randomized, double-blind, placebo-controlled trial. Semin Arthritis Rheum. 2009;39(3):203-212.

40. Berner T, Gold MS, Speiller M. Correlation of pain relief with function and global rating of disease in knee osteoarthritis: Data from randomized controlled trials of diclofenac sodium 1\% gel. Presented at the Academy of Nurse Practitioners 24th National Conference, June 17-21, 2009, Austin, TX.

41. Barthel HR, Peniston JH, Clark M, Gold MS. Correlation of pain relief with physical function in hand osteoarthritis: A randomized controlled trial post hoc analysis. Arthritis Res Ther. 2010;12(1):R7.

42. Barkin RL, Barkin SJ, Barkin DS. Perception, assessment, treatment, and management of pain in the elderly. Clin Geriatr Med. 2005;21(3):465-490.
43. Reynolds KS, Hanson LC, DeVellis RF, Henderson M, Steinhauser KE. Disparities in pain management between cognitively intact and cognitively impaired nursing home residents. J Pain Symptom Manage. 2008;35(4):388-396.

44. Easterling CS, Robbins E. Dementia and dysphagia. Geriatr Nurs. 2008;29(4):275-285.

45. Hajjar ER, Cafiero AC, Hanlon JT. Polypharmacy in elderly patients. Am J Geriatr Pharmacother. 2007;5(4):345-351.

46. Gregory S, Verdouw J. Therapeutic touch: Its application for residents in aged care. Aust Nurs J. 2005;12(7):23-25.

Therapeutics and Clinical Risk Management

\section{Publish your work in this journal}

Therapeutics and Clinical Risk Management is an international, peerreviewed journal of clinical therapeutics and risk management, focusing on concise rapid reporting of clinical studies in all therapeutic areas, outcomes, safety, and programs for the effective, safe, and sustained use of medicines. This journal is indexed on PubMed Central, CAS,

Submit your manuscript here: http://www.dovepress.com/therapeutics-and-clinical-risk-management-journal
EMBase, Scopus and the Elsevier Bibliographic databases. The manuscript management system is completely online and includes a very quick and fair peer-review system, which is all easy to use. Visit http://www.dovepress.com/testimonials.php to read real quotes from published authors. 